\title{
Medicalização e educação: análise de processos de atendimento em queixa escolar
}

\author{
Mariana Dias Benedetti ${ }^{1}$, http://orcid.org/0000-0002-8873-3238 \\ Danielle Mirian Marques de Moura Bezerra1', http://orcid.org/0000-0002-9361-3564 \\ Maria Carolina Guimarães Telles ${ }^{1}$, http://orcid.org/0000-0003-1512-704X \\ Luís Antônio Gomes de Lima1, http://orcid.org/0000-0002-9912-4315
}

\begin{abstract}
Resumo
A presente pesquisa teve como objetivo compreender os efeitos da medicalização através do uso de medicamento no processo de escolarização de crianças atendidas em um serviço psicológico-escola. Buscou-se, através da análise de prontuários, compreender o que levou ao diagnóstico como doença e consequentemente, à medicalização, e quais os efeitos para a criança, a família e a escola. Foram lidos 43 prontuários de um serviço psicológico-escola de um curso de psicologia e somente 2 atendiam aos critérios definidos pelas pesquisadoras. Os resultados obtidos com essa pesquisa foram divididos em duas categorias de análise: 1) a família e a criança medicalizada e 2) a medicina como panaceia. Como resultados, percebeu-se a continuidade de uma escola que discrimina quem não atenda ao modelo de aluno e família que se enquadre as suas modalidades predominantes de ensino, naturalizando como dificuldade individual fenômenos de origem sócio-histórico-cultural.
\end{abstract}

Palavras-chave: Processo educacional; psicologia educacional; escolas.

\section{Medicalization and Education: analysis of service processes in school complaints}

\begin{abstract}
The present research aimed to understand the effects of medicalization through the use of medication in the schooling process of children attending a psychological-school service. It was sought, through the analysis of medical records, to understand what led to the diagnosis as a disease and, consequently, to the medicalization, and what the effects for the child, the family, and the school. We read 43 medical records of a psychological-school service of a psychology course and only 2 met the criteria defined by the researchers. The results obtained with this research were divided into two categories of analysis: 1) the family and the medicalized child and 2) medicine as a panacea. As a result, we noticed the continuity of a school that discriminates against those who do not meet the model of student and family that fits their predominant teaching modalities, naturalizing as an individual difficulty phenomena of socio-historical-cultural origin.
\end{abstract}

Keywords: School complaints; educational psychology; schools.

\section{Medicalización y educación: análisis de procesos de atención en queja escolar}

\section{Resumen}

En la presente investigación se tuvo el objetivo comprender los efectos de la medicalización por intermedio del uso de medicinas en el proceso de escolarización de niños atendidas en un servicio psicológico-escuela. Se buscó, por intermedio del análisis de prontuarios, comprender lo que llevó al diagnóstico como enfermedad y consecuentemente, a la medicalización, y cuales los efectos para el niño, la familia y la escuela. Se leyó 43 prontuarios de un servicio psicológico-escuela de un curso de psicología y solamente 2 atendían a los criterios definidos por las investigadoras. Se dividieron, los resultados obtenidos con esa investigación, en dos categorías de análisis: 1) la familia y el niño medicada y 2) la medicina como panacea. Como resultados, se percibió la continuidad de una escuela que discrimina quien no atienda al modelo de alumno y familia que se encuadre a sus modalidades predominantes de enseñanza, naturalizando como dificultad individual fenómenos de origen socio-histórico-cultural. Palabras clave: Queja escolar; psicología escolar; escuelas.

1 Universidade São Judas Tadeu - São Paulo - SP - Brasil 


\section{Introdução}

Entende-se por medicalização um processo que envolve sofrimento psíquico que, de origem social, política e/ou escolar, é interpretado como problema de origem biológica e médica (Meira, 2012). O aluno que apresenta comportamentos desviantes, comportamentos que fogem à regra do que é aceitável e construído socialmente, dificuldades para aprender, um ritmo próprio que seja diferente dos colegas ou se comporta de maneira considerada não adequada para a escola, é muitas vezes encaminhado ao serviço médico, e sob o olhar da medicina é tratado como indivíduo doente, responsabilizando-se apenas o indivíduo por suas dificuldades, não se levando em conta aspectos sociais, como baixa qualidade de ensino e políticas públicas insuficientes para o estabelecimento efetivo do direito à educação para todos (Zucoloto, 2007).

Nas escolas, segundo Moysés (1990), há uma construção falsa entre doença e não aprendizado, essa construção corresponde a um modelo positivista de ciência e tal modelo leva em conta apenas o ponto de vista biológico.Um ponto de vista que desconsidera completamente o âmbito social no qual o indivíduo está inserido, tornando o social algo secundário e abstrato. A autora ressalta que são esses fatores, não explanados, não somente do âmbito social, mas também do político, econômico e cultural, que têm gerado um crescimento dessa forma de olhar o ser humano, sob a ótica da biologização, o que intensifica o processo de medicalização da sociedade. O aumento de diagnósticos de queixa escolar como doença produz severas consequências para essas crianças, tanto na visão que a escola atribui a elas, como no rótulo no qual se veem absorvidas. Em muitos dos casos, os professores acabam oferecendo atividades com níveis mais baixos e fora do contexto das aulas em relação aos programas oficiais, pois julgam que essas crianças não possuem o mesmo ritmo das demais da classe, o que acaba aumentando os problemas de escolarização desses alunos (Antônio, 2010).

A medicalização da vida escolar tem sido frequente em crianças que apresentam comportamentos diferentes daqueles esperados pela escola, o que tem causado uma epidemia de diagnósticos e um aumento considerável do uso de medicamentos por crianças e adolescentes em idade escolar. O fenômeno da medicalização é mais amplo que somente a prescrição de fármacos, envolve questões sociais, políticas e escolares. Segundo Meira (2012), "Essa 'epidemia' de diagnósticos produz na mesma escala uma 'epidemia' de tratamentos, muitos dos quais altamente prejudiciais à saúde, especialmente nos casos em que não seriam de fato necessários" (p. 136).

Segundo Fiore (2005)

A medicalização, como consequência dessa concepção fisicalista, suscita preocupações tanto físicas quanto psíquicas, em relação aos efeitos de longo prazo que implica das relações que produz, dos rótulos que se instalam e das dificuldades que o sujeito encontra a partir deles, determinados por uma série de obstáculos e sofrimentos que se interpõem na relação do sujeito com o mundo que o cerca. (p. 370)
Muitas vezes crianças que apresentam dificuldades de aprendizagem são "diagnosticadas" por professores que, observando o comportamento do aluno, rotulam-no com determinado transtorno. As escolas encaminham esses alunos para atendimento especializado e com frequência solicitam laudos e diagnósticos. Os serviços psicológicos-escola recebem essa demanda principalmente por, na maioria das vezes, atenderem a comunidade gratuitamente, ou de foram parcialmente gratuita. Nestes locais, estudantes em formação recebem orientação na forma de supervisão para exercer a prática profissional (Romaro \& Capitão, 2003).

Geralmente, os serviços psicológicos-escola organizam as informações dos atendidos em fichas e prontuários. Não é raro que pesquisadores busquem informações dessas fichas e prontuários para desenvolverem estudos de caracterização ou investigação que abram espaço para reflexões da prática clínica e formação de psicólogos.

Nakamura, Lima, Tada e Junqueira (2008) analisaram 634 prontuários de atendimento à queixa escolar do Serviço de Psicologia Aplicada (SPA) da Universidade Federal de Rondônia. As autoras constataram que $77 \%$ dos clientes com queixa escolar eram compostos por meninos com idade entre 5 e 14 anos, do ensino fundamental da rede pública de ensino, e a queixa apresentada com maior frequência foi de problemas de aprendizagem e de atitude. No estudo, as autoras chamam a atenção para práticas estigmatizantes e que centralizam as dificuldades de aprendizagem na própria criança.

Outra pesquisa realizada com a análise de prontuários foi a de Romaro e Capitão (2003), que caracterizaram a clientela que frequentou o serviço psicológico-escola da Universidade São Francisco no período de 1995 a 2000. No total, foram 590 fichas e prontuários analisados; destes, 248 eram de crianças, e a queixa mais frequente para esta faixa etária foi a de dificuldades escolares, com $19 \%$ dos casos.

Essas pesquisas revelam que a queixa escolar está presente em considerável proporção nos atendimentos realizados em serviços psicológico-escola. Devido a isso, a problematização do estigma e o atendimento com práticas que abordam o sofrimento psíquico em sua dimensão social e política são fundamentais; por serem considerados um centro de formação de psicólogos, é importante que tenham seus parâmetros de formação referenciados em estudos e reflexões que abarquem estas dimensões presentes no atendimento psicológico à queixa escolar.

Frente a essa realidade dos serviços psicológicos-escola propomo-nos, para o presente estudo, compreender os efeitos da medicalização no processo de escolarização de crianças atendidas em um serviço psicológico-escola na área de queixas escolares. Buscou-se, através da análise de prontuários, compreender o que levou ao diagnóstico como doença e, consequentemente, à medicalização, e quais os efeitos para a criança, a família e a escola. 


\section{Participantes}

A presente pesquisa consistiu no levantamento de 43 prontuários de crianças e jovens que passaram por atendimento em um serviço psicológico-escola, na cidade de São Paulo, entre 2007 e 2014. Foram analisados dois prontuários, cujas informações indicaram o uso demedicamentos pela criança ou adolescente atendido, sendo um correspondente ao ano de 2011 e o outro ao ano de 2014. Foram excluídos da pesquisa prontuários que indicassem a continuidade deste processo, ou seja, prontuários onde o processo terapêutico ainda não tivesse sido finalizado, com o objetivo de preservar a identidade dos envolvidos. Também foram excluídos da pesquisa prontuários nos quais os atendimentos realizados foram feitos em grupo.

\section{Material}

Para a pesquisa, foram consultados e analisados prontuários de crianças atendidas em um serviço psicológico-escola em São Paulo. Os prontuários são compostos por Termo de Consentimento Livre e Esclarecido (TCLE) devidamente assinado pelos responsáveis, um relatório de cada sessão realizada com o usuário durante o processo terapêutico, e um relatório síntese que contém informações de todo o processo feito, indicando o final do atendimento ou o seu encaminhamento para continuidade do processo terapêutico.

\section{Procedimento}

Deu-se início à pesquisa após a submissão e aprovação do projeto pelo Comitê de Ética em Pesquisa da Universidade São Judas Tadeu, sob protocolo $n^{\circ} 1.031 .353$ de 22/04/2015 e CAAE n 44065915.3.0000.0089. Foram lidos os relatórios-síntese de 43 prontuários, para que as pesquisadoras pudessem identificar se havia ou não casos de medicalização no processo terapêutico. Desses prontuários lidos, dois diziam respeito à medicalização; esses prontuários correspondentes aos anos de 2011 e 2014 foram lidos na íntegra. Após a leitura, foram identificados pontos em comum no relato dos atendimentos; essas semelhanças compõem as categorias de análise apresentadas como resultados desta pesquisa; são elas: 1) a família e a criança medicalizada, e 2) a medicina como panaceia. Conforme normas da instituição onde a pesquisa foi realizada, todos os prontuários foram lidos e analisados dentro das instalações da instituição.
Como resultados da pesquisa, foram encontrados somente 2 prontuários em um período de 8 anos de levantamento, cujo tema central era medicalização. Esses dados chamaram a nossa atenção, pois é um número muito pequeno diante da realidade de prescrições de metilfenidado. Sabemos que o universo pesquisado é limitado, e encontrar um número tão baixo de prontuários nos leva a pensar para onde essas crianças estão sendo encaminhadas que não os serviços de psicologia-escola. Com isso, usou-se como critério de inclusão, prontuários que indicassem o uso de remédio pelas crianças ou adolescentes, mesmo sabendo que o fenômeno é mais amplo que somente a prescrição de fármacos.

Com base nesses dois prontuários, foi iniciado um trabalho de análise de discurso, onde foram elaboradas duas categorias de análise; não há nesse caso, a pretensão de fazer uma análise geral sobre a medicalização, mas sim encontrar pontos em comum entre os dois prontuários e refletir sobre tais aspectos.

Considerando a proposta desta pesquisa, a seguir será apresentada uma síntese dos prontuários lidos e analisados; os dados referentes à medicalização serão apresentados tal como constam nos prontuários. A fim de proteger a identidade dos usuários do serviço psicológico-escola todos os nomes são fictícios, e as idades dos usuários correspondem ao período em que foram atendidos pelo serviço psicológico-escola.

\section{Resenhas dos prontuários:}

\section{Prontuário 1:}

\begin{tabular}{|lc|}
\hline Nome fictício & Gustavo \\
Período de atendimento & 03/03/2011 a 05/11/2011 \\
Total de sessões & 25 \\
Total de faltas & 2 \\
Demanda Apresentada & Déficit de Aprendizagem \\
\hline
\end{tabular}

Quadro 1 - Síntese do Processo Terapêutico Gustavo

Gustavo cursava a $7^{\circ}$ série do ciclo II do ensino fundamental no período que foi atendido.

Primeiramente Gustavo foi atendido em uma disciplina relacionada à Análise do Comportamento. Tinha 13 anos no momento em que foi atendido.

A criança foi diagnosticada com TDAH por um psiquiatra.

Começou a tomar Metilfenidato (Ritalina) em janeiro de 2010. 
A mãe relata que "ele fica calmo com os remédios, mais fácil de controlar" (SIC).

O pai acredita que as dificuldades de aprendizagem do filho estejam relacionadas à má adaptação ao ensino fundamental.

Segundo o prontuário, durante as sessões a criança apresentou-se afetuosa e interessada nas atividades propostas.

Quando questionado sobre o que ele pensa do uso de medicamentos, e ele disse que melhorou após o uso, mas que as professoras continuavam reclamando.

O psiquiatra informa que o remédio funciona como um suporte ao comportamento de Gustavo e que pretende continuar com a medicação por cerca de 2 anos.

A coordenadora da escola de Gustavo não acredita no diagnóstico de TDAH e diz que "é a mãe que não sabe educar os filhos" (SIC).

Devido à melhora dos comportamentos e do seu desempenho escolar o caso foi encerrado.

\section{Prontuário 2:}

\begin{tabular}{|lc|}
\hline Nome fictício & João \\
\hline $\begin{array}{l}\text { Período de } \\
\text { atendimento }\end{array}$ & $12 / 04 / 2014$ a 07/06/2014 \\
\hline Total de sessões & 7 \\
\hline Total de faltas & 2 \\
\hline Demanda Apresentada & Dificuldade de Atenção \\
\hline
\end{tabular}

\begin{tabular}{|l|}
\hline Quadro 2 - Síntese do Processo Terapêutico João \\
\hline \\
\hline $\begin{array}{l}\text { João cursava o } 9^{\circ} \text { ano do ensino fundamental II no } \\
\text { período que foi atendido e tinha } 14 \text { anos. }\end{array}$ \\
\hline $\begin{array}{l}\text { A criança é natural da Praia Grande, mudou-se para São } \\
\text { Paulo devido doença da avó. }\end{array}$ \\
\hline $\begin{array}{l}\text { A primeira sessão foi realizada com o pai, que levou } \\
\text { uma carta do psiquiatra, evidenciando o diagnóstico de } \\
\text { Déficit de Atenção/Hiperatividade (TDAH) e Transtorno } \\
\text { de Linguagem. }\end{array}$ \\
\hline
\end{tabular}

João fazia uso de Metilfenidato (Ritalina) e Sertralina (antidepressivo), que segundo o pai, esses remédios servem para "ativar a mente" (SIC).

Na Praia Grande, João não tinha reclamações, após a mudança para São Paulo a criança perdeu o interesse pela escola.

O João relata que a escola é muito rígida e que por vezes, parece uma prisão.

A criança passou por uma consulta médica onde foi diagnosticada pressão alta e por esse motivo interrompeu o uso de Ritalina.

João relatou: "a minha dificuldade é só de prestar atenção, não é de estudar" (SIC).

A família passou a faltar repetida vezes sem justificativas. Seguindo os critérios da instituição, após diversas tentativas de contato, o caso foi encerrado.

Após a leitura dos prontuários, foram identificados temas e pontos comuns entre eles, a partir dos quais foi possível criar categorias de análise para a discussão do fenômeno da medicalização nestes atendimentos: a família e a criança medicalizada e a medicina como panaceia.

\section{A família e a criança medicalizada}

Esta categoria discute e analisa os dados dos prontuários referentes às famílias das duas crianças que passaram pelo serviço psicológico-escola e que vivenciaram o fenômeno da medicalização. Apresentaremos relatos dos pais e das crianças a fim de compreender como foi vivenciado esse processo, conforme destacaremos a seguir.

Detemo-nos em relatos como o do pai de João, que diz "o remédio serve para ativar a mente", e da mãe de Gustavo, que na segunda sessão realizada relata para as terapeutas "com o medicamento é mais fácil de controlar, ele obedece mais", revelando que eles não questionam o diagnóstico, mas percebem a vantagem em poder controlar os problemas. O pai de Gustavo não acredita que o medicamento tenha efeito positivo para o filho, nem mesmo algum efeito; relata não observar diferença. Esse pai se opõe à escola, critica o fato de sempre reclamarem do filho e não verem as suas potencialidades, mas isso é logo explicado e deixa de ser considerado, quando no relatório de descrição da sessão as terapeutas expõem que "o pai trabalha muito, possui pouco tempo" para acompanhar o processo de escolarização do filho; o pai parece ser mais questionador, mas é calado por sua condição de pai trabalhador considerado ausente, exemplo do preconceito que permeia o ambiente escolar em relação às famílias dos alunos. 
Está presente nas escolas a crença que diz respeito à organização das famílias. Culpabilizar a condição social do aluno, a família considerada desestruturada, agressiva, pouco afetiva - na visão de quem julga - é o movimento que se faz mais presente, mas traz consequências, como a estigmatização de crianças saudáveis que, de tanto serem rotuladas, incorporam essa máscara da doença; quando baixam as guardas do autoconceito, surge a criança doente, que, como Gustavo, não quer parar de tomar o medicamento, pois já se acostumou a ele, ou nas palavras de João, "a minha dificuldade é só de prestar atenção, não é de estudar" (Collares \& Moysés, 2011).

Apesar do preconceito e rotulação vividos pelas famílias nas escolas, o acesso à informação através da rapidez produzida pela internet é impressionante; em segundos se sabe o que está acontecendo do outro lado do mundo. Os brinquedos são cada vez mais tecnológicos, mecanizados, controlados por controles e pilhas. Com isso, a escola fica cada vez menos interessante para as crianças, pois lá espera-se que elas fiquem sentadas, quietas e prestando atenção em coisas que são chatas e que não fazem sentido algum. De acordo com B. P. Souza (2007), a análise dos cadernos escolares, aliada a observações em sala de aula, revelam com frequência, aulas em que predominam os exercícios repetitivos e mecânicos, como cópias e séries de exercícios desprovidos de sentido.

A realidade das escolas públicas no Brasil não é muito animadora, os moldes que utilizados para se ensinar as crianças são arcaicos. Citando Viégas e Oliveira (2014) "Qualquer pesquisador que se disponha a conhecer a vida escolar, vai deparar-se com uma realidade a partir da qual a escola participa ativamente da produção do fracasso escolar"(p. 51). Nos prontuários foram discutidas questões referentes à escola, ao seu funcionamento e a sua falta de manejo para lidar com as dificuldades específicas de cada criança, valendo-se de laudos onde a "culpa" de não aprender passa a ser unicamente da criança, sem considerar o meio em que está inserida.

Em ambos os prontuários eleitos para a análise, as crianças foram diagnosticadas com Transtorno de Déficit de Atenção e Hiperatividade (TDAH), que segundo o DSM IV (APA, 2002) "consiste num padrão persistente de desatenção e/ou hiperatividade-impulsividade, mais frequente e grave do que aquele tipicamente observado nos indivíduos em nível equivalente de desenvolvimento" (p. 112).

Gustavo relata ter dificuldade em prestar atenção e não em estudar; já João apresenta comportamento agressivo e agitado durante as sessões. Não fica claro nos prontuários em qual subtipo do TDAH se enquadra o diagnóstico de João e Gustavo. Desatento, hiperativo-compulsivo ou combinado; a terminologia muda, mas os efeitos estigmatizantes permanecem e afetam negativamente a criança, a família, os professores, a confiança, o autoconceito, a esperança no contexto da escolarização.

O que se apresenta através dos dois prontuários analisados nesta pesquisa é reflexo da história da medicina na constituição da psicologia educacional. História que, no Bra- sil, tem suas raízes na primeira metade do século passado, época em que predominava no imaginário social que a miscigenação das raças, o convívio com os negros, doentes mentais ou físicos, era de risco, ameaçava a integridade da população. Neste período, segundo Patto (1999), "Os primeiros trabalhos brasileiros de interesse psicológico foram teses de conclusão de curso nas faculdades de medicina da Bahia e do Rio de Janeiro" (p.104). Com o passar do tempo, esses pesquisadores formados em medicina, passaram a lecionar nas escolas normais e nos cursos de graduação e especialização em psicologia, os mesmos que outrora se formaram em uma época em que predominavam as teorias racistas (Patto, 1999).

Portanto, para pensar a ciência do poder médico atual é preciso resgatar as transformações políticas e sociais de uma nova forma de organização social decorrentes do modo de produção capitalista. Há uma nova concepção de família, uma nova ordem familiar, com divisão de papéis, responsabilidades, tal como se apresenta até os dias atuais. Neste novo modelo de família surge uma nova imagem da infância. Além disso, o espaço urbano também sofre transformações; surgem as cidades, que se expandem e levam também à expansão de problemas e doenças (Moysés \& Collares, 2014).

Surge então a puericultura, que segundo Del Ciampo, L. A., Ricco, Daneluzzi, Del Ciampo, I. R. L., Ferraz e Almeida (2006), é uma área da pediatria voltada para prevenção e promoção da saúde infantil, de modo que a criança consiga chegar à vida adulta saudável e sem problemas advindos da infância; segundo o autor, para que a puericultura seja colocada em prática, é necessário que o médico conheça o ambiente social e familiar no qual a criança está inserida, pois mesmo que suas ações sejam dirigidas à criança, tais ações vão se refletir no contexto social e, principalmente, no contexto familiar em que a criança está inserida.

Com o discurso de civilizar os menos favorecidos, as crianças foram o primeiro alvo dessa intervenção, que primeiramente levava senhoras burguesas à periferia a fim de ensinar as pobres mães a cuidar de seus filhos, alimentá-los e educá-los (Moysés \& Collares, 2014).

Essas medidas carregadas de preconceito logo ganharam um aliado, a medicina positivista, que segundo Decotelli, Bohrer e Bicalho (2013) "ocupa todo o espaço social, com a finalidade de proteger a saúde e de identificar e eliminar as patologias; define-se o homem modelo; privilegia-se a normalidade" (p.453). A lógica utilizada passa a ser a de que é preciso ter saúde para aprender, mas para ter saúde, é preciso se ter um conhecimento prévio, relacionado aos cuidados de higiene que a infância exige.

Cria-se no imaginário social uma relação direta entre pobreza e fracasso escolar, bem como uma confiança cega e inquestionável no poder médico, que possui uma postura onipotente diante do paciente. De um lado está alguém que possui uma crença na verdade científica, do outro lado uma família que se utiliza dos serviços hospitalares públicos, que na realidade social atual, trata-se de um serviço público destinado aos menos favorecidos, que em alguns casos são famílias de baixa renda, com a marca da exclusão social e 
política que o distancia desse mundo da razão, que prega a verdade sem questionamentos (Martins, 2004).

\section{A medicina como panacéia}

Nos prontuários lidos e selecionados para análise, as crianças chegam aos consultórios médicos, pois não conseguem acompanhar os colegas de classe; essas crianças não atendem os critérios que a escola impõe e por esse motivo são encaminhadas; durante a consulta são diagnosticadas com TDAH, e por diversas vezes acaba sendo-lhe prescrito algum medicamento, na maioria das vezes o metilfenidato, para ajudar essa criança a ter "bons resultados na escola".

Um fator relevante trazido nos prontuários é o tempo no qual a criança irá fazer uso do metilfenidato. Em um dos prontuários o médico diz que pretende tirar a medicação após dois anos de uso, porém não tem certeza sobre esse dado, pois, segundo o médico, o remédio serve como um suporte para a vida da criança. Segundo Ortega e cols. (2010), a partir do momento em que se recebe o diagnóstico de TDAH, ele perdura por toda a vida, sendo algo imutável e permanente, torna-se necessário fazer uso da medicação por tempo indeterminado; porém, a questão do tempo de uso do metilfenidato é aspecto muito preocupante, pois, segundo Pastura e Matos (2004), o uso prolongando do metilfenidado traz efeitos colaterais, como dependência, efeitos cardiovasculares e possível redução da estatura; com isto é necessário que haja um maior controle por parte da medicina na prescrição de tal medicamento.

Um aspecto de suma importância trazido no prontuário de Gustavo é a suposta eficácia que o remédio tem na melhora dele. Em determinado momento do processo terapêutico, sua mãe diz que "fica mais fácil de controlar o comportamento dele quando toma o remédio" (SIC), enquanto o pai de Gustavo diz que o filho "muda muito pouco, quase nada" (SIC).Segundo uma pesquisa realizada por Andrade e Scheuer (2004), o uso do metilfenidato em $25 \%$ das crianças estudadas não teve efeito, enquanto em $75 \%$ das crianças estudadas houve alguma melhora em relação à coordenação motora e aprendizagem em curto prazo, porém não fica claro nesse artigo como essa melhora pode ser objetivada. O que chama a atenção é que em $25 \%$ dos casos as crianças não responderam ao uso da medicação, o que segundo Santos, Silva, Luzio, Yasui e Dionisio (2012), é um dado relevante, pois faz os pesquisadores pensarem que ainda são necessários mais estudos sobre o diagnóstico de TDAH e sobre a medicação.

Pensando que o diagnóstico de TDAH e o uso de remédios para esse tipo de transtorno aumenta significativamente a cada ano,o que pode ter sido causado pela expansão do acesso da população às escolas públicas, se faz necessário pensar sobre o movimento da medicina acerca do fenômeno da medicalização.Sem dúvida, os avanços tecnológicos no campo da medicina neurocientífica são extremamente significativos; é possível ter acesso ao funcionamento físico-químico do cérebro de uma pessoa através de neuroimagens.
Esses avanços trazem grande prestígio à área da medicina, mas principalmente à medicina psiquiátrica, que antes desses grandes avanços tinha pouca notoriedade diante das outras especialidades médicas. Junto com esta evolução, na década de 50 , aparecem os psicofármacos, entre eles, o metilfenidato, que ganham grande visibilidade, rompendo a relação que a psiquiatria tinha com a psicanálise, já que os remédios têm como objetivo atender a um rigor científico baseado na biologia, privilegiando a eficácia e a rapidez,o que difere da psicanálise, que não atende essas demandas de velocidade da sociedade (Santos \& cols.2012).

Segundo um estudo feito por Czobot, Eizirik, Cunha, Langleben e Rohde (2001), mesmo com avanços no campo da medicina, os autores explicam que os exames de neuroimagens não são suficientes para um diagnóstico do TDAH; ainda neste artigo, os autores dizem que há uma variação na avaliação das neuroimagens, pois não há, seja por meio quantitativo, qualitativo ou por protocolo computadorizado, um padrão de critérios para confirmar ou excluir diagnóstico, por isso não sendo possível usar a neuroimagem no diagnóstico de TDAH.

Na década de 50 criou-se uma relação entre o uso de medicamentos e a rápida melhora dos sintomas de doenças, através da "revolução psicofarmacológica"; os remédios ganharam espaço rompendo com a psicanálise. Segundo os autores, Santos e cols. (2012), os medicamentos atendem um padrão científico exigido pela sociedade dessa época, o que vai de encontro à proposta da psicanálise, que não acompanha dessa maneira a velocidade exigida pelo contexto social em questão. Ainda citando Santos e cols. (2012), o metilfenidato é um psico estimulante que faz parte das anfetaminas, como a cocaína, e se administrada em doses corretas, pode auxiliar na melhora da atenção e no controle da fadiga.

Tal medicamento era prescrito às pessoas com doenças mentais e idosas, a fim de auxiliar na fadiga; o medicamento não tinha que ser prescrito obrigatoriamente com um diagnóstico. Já nos dias de hoje, é importante ressaltar que a prescrição de tal medicamento está intimamente ligada ao diagnóstico de TDAH (Transtorno de Déficit de Atenção e Hiperatividade). Atualmente, segundo Itaborahy e Ortega (2011), o metilfenidato é o psico estimulante mais consumido no mundo todo; inclusive no Brasil, onde sua comercialização foi iniciada por volta do ano de 1998, com o seu consumo crescendo de maneira abrupta.

As crianças com dificuldades de aprendizagem ou comportamentos ditos desviantes são encaminhadas aos consultórios médicos e, com base no relato da família sobre a criança, lhe são prescritos psico fármacos, na sua grande maioria o metilfenidato que, segundo os médicos, vão fazer com que a criança melhore seu desempenho escolar e seu comportamento; porém, essa prescrição acontece com um exame clínico pautado, na grande maioria das vezes, apenas no relato dos pais; não há, em muitos casos, uma investigação mais profunda da real condição da criança frente a essas dificuldades.

Levando em conta o que já foi discutido nesta categoria, é importante pensar em qual lugar a medicina se encon- 
tra na psicologia escolar. Segundo Patto (1999), no Brasil a psicologia nasce no âmbito da medicina, tanto que os primeiros estudos feitos com testes psicológicos foram realizados por médicos. Segundo a autora, a maneira da medicina ver os transtornos psicológicos ia de encontro da maneira como a psicanálise pensava esses fenômenos, esta influenciada pelo movimento higienista, instaurado no Brasil no começo do século XX. A educação foi pensada, no começo do século, em uma concepção racista e biologizante sobre o comportamento humano, e a partir deste pensamento é que surgiram as ideias que influenciaram os rumos da política, da pesquisa e das práticas educacionais (Patto, 1999).

Com o aumento abrupto do consumo de medicamentos que dizem superar os problemas de aprendizagem das crianças, é importante levantar alguns questionamentos acerca do fenômeno estudado. Será que a aceitação absoluta dos diagnósticos em queixa escolar é o melhor caminho para a resolução dos problemas relacionados à educação, levando em conta tamanha complexidade do fenômeno? $\mathrm{O}$ que é preciso para que médicos, professores, psicólogos, familiares e até mesmo as crianças ampliem sua visão questionadora e se envolvam com debates e reflexões acerca do movimento social, político, econômico e cultural atual? Será que, um diagnóstico assim concebido, é pertinente em relação à complexidade do fenômeno em causa? Será que tomando essa quantidade de medicamentos tarja preta essas crianças vão, de fato, obter melhores resultados na escola? Será que a busca incessante pelos melhores resultados nas escolas atualmente não seria algo que anda na contramão da educação? Será que não existe outra maneira não-medicalizante para ajudar esses estudantes?

\section{Discussão}

A partir da análise dos 2 prontuários selecionados através dos critérios estabelecidos no projeto, foram elaboradas 2 categorias de análise face ao problema de pesquisa. Essas categorias foram criadas com base nos pontos em comuns e relevantes encontrados em ambos os prontuários e, também, com o intuito de entender de maneira mais profunda o fenômeno da medicalização da vida escolar, já que esse tema, ainda, gera algumas discussões e questionamentos.

Fez-se necessário discutir sobre a família e a criança medicalizada e sobre a medicina como cura de todos os males. A reflexão presente nas categorias de análise configura-se um exercício de aprofundamento nos temas, sem a pretensão de mapear de forma completa a medicalização, diante da complexidade desse fenômeno,também em função dos poucos prontuários encontrados no recorte desta pesquisa, fato que não correspondia às expectativas das autoras no início deste trabalho.

Constantemente ouve-se um novo nome de transtorno ou síndrome no campo da psiquiatria, e com maior frequência são indicados fármacos com a promessa de alteração dos estados psíquicos "desviantes". A indústria farmacêutica tem tido um crescimento acelerado, sendo o segundo setor mais rentável do mundo, perdendo apenas para grandes bancos internacionais (Machado \& Ferreira, 2014).

Tendo em vista os resultados apresentados e os grandes índices de prescrição de Metilfenidato, levantou-se a hipótese de que as crianças estão sendo encaminhadas para outros serviços que não o serviço-psicológico escola em questão, dado que cada vez mais cedo as crianças são submetidas a diagnósticos psicopatologizantes,sendo a partir destes prescritos o uso de psicofármacos, que tentam tratar os sintomas desconsiderando o contexto escolar, familiar, social e histórico no qual a criança está inserida (Guarido, 2011).

Pensando a medicalização nos dias atuais, Lemos (2014) pontua que "por meio de racionalidades medicalizantes, o crescente mercado da saúde, da educação e da segurança encontra na normalização um mecanismo de silenciamento da produção da diferença e de controle de qualquer prática de resistência civil na sociedade contemporânea" (p.486). Trata-se de um mecanismo que não se restringe à área da educação, conforme nos propusemos a estudar nesta pesquisa; mas abrange a sociedade de forma ampla, sendo reflexo das mudanças socioeconômicas e culturais. A competitividade, a velocidade das informações, o individualismo, a procura incessante pelo bem-estar, são exemplos de condutas que levam a sociedade a se render à "cura de todos os males".

\section{Referências}

American Psychiatric Association [APA]. (2002). Manual Diagnósticos e Estatístico de Transtornos Mentais DSM-IV-TR. Porto Alegre: Artmed.

Andrade, E.R.; Scheuer, C. (2004). Análise da eficácia do Metilfenidato usando a versão abreviada do questionário de Conners em Transtorno de Déficit de Atenção e Hiperatividade. Arquivos de Neuro-Psiquiatria, 62(1), 81-85.

Antônio, G.D.R. (2010). Dislexia: O excesso de diagnósticos e o reflexo na vida das crianças. In: Instituto de Estudos da Linguagem da Universidade de Campinas (Org.), Anais do Seminário de Teses em Andamento dos Cursos de Pós-Graduação do Instituto de Estudos da Linguagem da Universidade de Campinas (vol. 4, pp.406-416). São Paulo: Campinas.

Collares, C.A.L.; Moysés, M.A.A. (2011). Preconceitos no cotidiano escolar: a medicalização do processo ensino-aprendizagem. In: Conselho Regional de Psicologia de São Paulo; Grupo Interinstitucional Queixa Escolar (Orgs.), Medicalização de crianças e adolescentes: conflitos silenciados pela redução de questões sociais a doenças de indivíduos (pp. 193-213). São Paulo: Casa do Psicólogo.

Czobot, C.M.; Eizirik, M.; Cunha, R.D.; Langleben, D.; Rohde, L.A (2001). Neuroimagem no transtorno de déficit de atenção/ hiperatividade. Revista Brasileira Psiquiatria, 23(Supl I), 32-5. 
Decotelli, K.M.; Bohrer, L.C.T.; Bicalho, P.P.G. (2013). A droga da obediência: medicalização, infância e biopoder - Notas sobre clínica e política. Psicologia: Ciência e profissão, 33 (2), 446-459.

Del Ciampo, L.A.; Ricco, R.G.; Daneluzzi, J.C.; Del Ciampo, I.R.L.; Ferraz, I.S.; Almeida, C.A.N. (2006). O Programa de Saúde da Família e a Puericultura. Ciência \& Saúde Coletiva, 11(3), 739743.

Fiore, M.A. (2005). Medicalização do corpo na infância: Considerações acerca do Transtorno de Déficit de Atenção e Hiperatividade. Revista Mnemosine, 1 (1), 364-380.

Guarido, R. (2011). A biologização da vida e algumas implicações do discurso médico sobre a educação. IN: Conselho Regional de Psicologia de São Paulo; Grupo Interinstitucional Queixa Escolar (Orgs.), Medicalização de crianças e adolescentes: conflitos silenciados pela redução de questões sociais a doenças de indivíduos (pp. 193-213). São Paulo, SP: Casa do Psicólogo.

Itaborahy, C.; Ortega, F. (2011). O metilfenidato no Brasil: uma década de publicações. Temas Livres, 803-816.

Lemos, F.C.S. (2014). A medicalização da educação e da resistência no presente: disciplina, biopolítica e segurança. Psicologia Escolar e Educacional, 18(3), 485-492.

Machado, L. V.; Ferreira, R. R. (2014). A indústria farmacêutica e a psicanálise diante da epidemia de "Depressão": respostas possíveis. Psicologia em Estudo, 19(1), 135-144.

Martins, A. (2004). Biopolítica: O poder médico e a autonomia do paciente em uma nova concepção de saúde. Interface comunicação, saúde, educação, 8 (14), 21-32.

Meira, M.E.M. (2012). Para uma crítica da medicalização na educação. Psicologia Escolar e Educacional, 16 (1), 135-142.

Moysés, M.A.A.; Collares, C.A.L. (2014). Mais de um século de patologização da educação. Fórum: Diálogos em Psicologia, 1 (1), 50-64.
Moysés, M.A.A. (1990). Fracasso escolar: uma questão médica? Em: Toda criança é capaz de aprender? Série idéias n6, Fundação para o Desenvolvimento da Educação, 40-46.

Nakamura, M.S.; Lima, V.A.A.; Tada, I.N.C.; Junqueira, M.H.R. (2008). Desvendando a queixa escolar: um estudo no Serviço de Psicologia da Universidade Federal de Rondônia. Psicologia Escolar e Educacional, 12 (2), 423-429.

Ortega, F.; Barros D.; Caliman L.;, Itaborahy, C.; Junqueira L.; Ferreira C.P. (2010). A ritalina no Brasil: produções, discursos e práticas. Interface Comunicação Saúde Educação, 14 (34), 499510.

Pastura, G.; Mattos, P. (2004). Efeitos Colaterais do Metilfenidato. Revista de Psiquiatria Clínica, 31 (2), 100-104

Patto, M.H.S. (1999). A produção do fracasso escolar: histórias de submissão e rebeldia. São Paulo, SP: Casa do Psicólogo.

Romaro, R.A.; Capitão, C.G. (2003). Caracterização da clientela da clínica-escola de psicologia da Universidade São Francisco. Psicologia: Teoria e Prática, 5 (1), 111-121.

Santos, K.Y.P.; Silva, A.C.P.; Luzio, C.A.; Yasui, S.; Dionísio, G.H. (2012). A explosão do consumo de Ritalina. Revista de Psicologia da UNESP, 11(2), 44-57.

Souza, B.P. (2010). Funcionamentos escolares e produção de fracasso escolar e sofrimento. In: Souza, B. P. (Org.), Orientação à Queixa Escolar (pp. 240-277). São Paulo, SP: Casa do Psicólogo.

Viégas, L.D.S.; Oliveira, A.R.F. (2014). TDAH: Conceitos Vagos, Existência Duvidosa. Nuances: estudos sobre Educação, 25(1), 39-58.

Zucoloto, P.C.S.V. (2007). O médico higienista na escola: As origens históricas da medicalização do fracasso escolar. Revista Brasileira do Crescimento e Desenvolvimento Humano, 17 (1), 136-145. 


\section{Sobre os autores}

Mariana Dias Benedetti (mdbenedettis@gmail.com)

Núcleo de Psicologia Escolar. Universidade São Judas Tadeu. São Paulo.

http://orcid.org/0000-0002-8873-3238

Danielle Mirian Marques de Moura Bezerra (daniellemirian@gmail.com) Núcleo de Psicologia Escolar. Universidade São Judas Tadeu. São Paulo-SP. http://orcid.org/0000-0002-9361-3564

Maria Carolina Guimarães Telles (mariacaroltelles@gmail.com )

Núcleo de Psicologia Escolar. Universidade São Judas Tadeu. São Paulo-SP. http://orcid.org/0000-0003-1512-704X

Luís Antônio Gomes de Lima (luisglima@uol.com.br) Núcleo de Psicologia Escolar. Universidade São Judas Tadeu. São Paulo-SP. http://orcid.org/0000-0002-9912-4315 unrestricted use, distribution and reproduction in any medium, provided the original article is properly cited. 
